\title{
Rare case of an isolated myeloid sarcoma presenting as dysphagia
}

\begin{abstract}
Myeloid sarcoma (MS) is an unusual neoplasm whose understanding is principally based on the case reports and/or theoretically dated contributions. MS represents the proliferation of myeloblasts of acute myeloid leukemia (AML) at extramedullary sites. While extramedullary involvement in AML is unusual in itself, isolated (de novo) MSs that is MSs devoid of any bone marrow involvement are exceptionally rare. The present case report study expands the gamut of our acquaintance showing that MS can occur de novo, with no apparent sign or symptom of concomitant hematological disease and may show a significant response to treatment this may be omitted here. This case reports described a middle-aged male presenting as with dysphagia with isolated MS in the stomach, a very rare site.
\end{abstract}

Keywords: Gastric, immunohistochemistry, myeloid sarcoma, positron emission tomography-computed tomography

\section{INTRODUCTION}

Myeloid sarcoma (MS), also known as granulocytic sarcoma or chloroma (owing to its green color attributed to the enzyme myeloperoxidase), is a pathologic diagnosis for an extramedullary propagation of blasts of one or more of the myeloid lineages that upset the usual architecture of the tissue in which it is found. It has also been addressed as myeloblastoma and extramedullary myeloid cell tumor. ${ }^{[1]} \mathrm{MS}$ is incorporated as one of the major subgroups of myeloid neoplasm and acute leukemia in the WHO classification and occurs usually either concurrently or following a previously recognized acute myeloid leukemia (AML). It may rarely occur as a secluded leukemic tumor or precede the appearance of blood or bone marrow (BM) disease. ${ }^{[2]}$ Less often, MS may occur in association with a myeloproliferative neoplasm or myelodysplastic disorder. In published series, MS is often incorporated with extramedullary disease; however, these two phenomena may not share the same outcome and may need to be treated differently. In this case report, we focus mainly on isolated MS and its diagnosis and treatment. Literature is mainly composed of case reports as large series are seldom reported owing to the rarity of this disorder. ${ }^{[3]}$

\begin{tabular}{|l|c|}
\hline \multicolumn{2}{|c|}{ Access this article online } \\
\hline \multirow{2}{*}{$\begin{array}{l}\text { Website: } \\
\text { www.asjo.in }\end{array}$} & Quick Response Code \\
\hline \multirow{2}{*}{$\begin{array}{l}\text { DOI: } \\
\text { 10.4103/ASJO.ASJO_19_18 }\end{array}$} & \\
&
\end{tabular}

\section{CASE REPORT}

A 42-years-old male with no comorbidity presented in our institution with chief complains of dysphagia which was intermittent and more with solids along with pain in epigastrium radiating to back for the last 1 month.

He underwent an endoscopy that revealed a large growth with overlying normal mucosa suggestive of the submucosal or extrinsic lesion at the gastroesophageal junction $(40 \mathrm{~cm})$. A computed tomography (CT) chest and abdomen was done and it revealed a raised right hemidiaphragm with adjacent basal atelectasis of lung parenchyma and thickened gastric

\section{Rishu Sangal, Vivek Mahawar, AnKush Jajodia ${ }^{1}$, Himanshu Mahanthi ${ }^{2}$, Venkata Pradeep Babu Koyyala ${ }^{2}$}

Departments of Surgical Oncology, ${ }^{1}$ Radiology and ${ }^{2}$ Medical Oncology, Rajiv Gandhi Cancer Institute and Research Centre, New Delhi, India

\section{Address for correspondence: Dr. Venkata Pradeep Babu Koyyala, \\ Room: 2262, $2^{\text {nd }}$ Floor C Block, Sector -5 , Rohini, Rajiv Gandhi Cancer Institute and Research Centre, New Delhi - 110 085, India. E-mail: pradeepbabu.koyyala@gmail.com}

This is an open access journal, and articles are distributed under the terms of the Creative Commons Attribution-NonCommercial-ShareAlike 4.0 License, which allows others to remix, tweak, and build upon the work non-commercially, as long as appropriate credit is given and the new creations are licensed under the identical terms.

For reprints contact: reprints@medknow.com

How to cite this article: Sangal $R$, Mahawar V, Jajodia A, Mahanthi $H$, Koyyala VP. Rare case of an isolated myeloid sarcoma presenting as dysphagia. Asian J Oncol 2018;4:30-3. 
wall in the fundal region not extending to the esophagus, probably suggestive of gastric malignancy.

An endoscopic-guided gastric biopsy was done in our institution which revealed infiltration of lamina propria by myeloid blasts, consistent with an extramedullary granulocytic sarcoma (MS). On immunohistochemistry (IHC), the tumor cells were positive for LCA, MPO, CD117, CD34, c-kit, and Bcl12. Tumor cells were negative for CD3, CD20, CD 38, CyclinD1, CK, MUM1 (P), CD10, Bcl16, CD79a, Tdt, CD56, Pax5, Alk1, CD30, CD138, CD4, CD8, CD5, CD2, and CD7. The tumor cell Ki67 proliferation index was $90 \%-95 \%$.

A BM trephine biopsy done showed a normocellular BM biopsy with normal morphology, hence, turned out to be negative for lymphoma/leukemia involvement. Further, IHC for CD34 revealed $<1 \%$ CD34-positive cell. Hematological and biochemical parameters did not reveal any significant abnormality.

The AML Combo quest (NPM1 mutation analysis, FLT3 mutation analysis, and CEBPA mutation analysis) by polymerase chain reaction and gel electrophoresis and internal tandem duplication did not detect any mutations.

Baseline 18-F fluorodeoxyglucose (FDG) positron emission tomography-computed tomography (PET-CT) was performed at our institution for staging. It shows a metabolically active stomach lesion with lymph nodal, peritoneal, omental, and left pleural involvement. No other metabolically active disease was detected elsewhere in the body [Figure 1].

The patient was confirmed to have gastric MS on the basis of imaging, gastric biopsy, and molecular examination.
AML induction chemotherapy with injection daunorubicin and injection cytarabine ( $3+7$ regimen) with prehydration, posthydration, and antiemetic was initiated.

Postinduction chemotherapy PET CT was done for the response evaluation, which showed mild wall thickening involving fundus and proximal body along lesser and greater curvature of the stomach (maximum thickness $1.4 \mathrm{~cm}$, SUV max 3.3) with heterogeneous tracer uptake [Figure 2].

Given the good response, the patient was given $1^{\text {st }} \mathrm{AML}$ consolidation chemotherapy with high-dose Ara-C. The patient was admitted on day +10 post $1^{\text {st }} \mathrm{AML}$ consolidation chemotherapy with complaints of generalized weakness. Blood investigations showed pancytopenia. BM biopsy showed features of pure red cell aplasia. He was started on IV fluids, antifungals, blood and blood products, and granulocyte-colony-stimulating factor along with other supportive care.

Postinduction therapy, on consolidation regimen a repeat PET-CT, shows ill-defined wall thickening involving fundus and proximal body along lesser and greater curvature of the stomach (maximum thickness $0.8 \mathrm{~cm}$, SUV max 2.3) with heterogeneous tracer uptake. As compared to patient's earlier study, stomach lesion shows a decrease in extent and metabolic activity suggestive of good response to treatment [Figure 3].

The patient was admitted for allogenic stem cell transplant and is scheduled for traumatic brain injury (TBI) as per protocol. The allogenic peripheral blood stem cell transplant was done after giving conditioning regimen with fludarabine/TBI-based regimen.
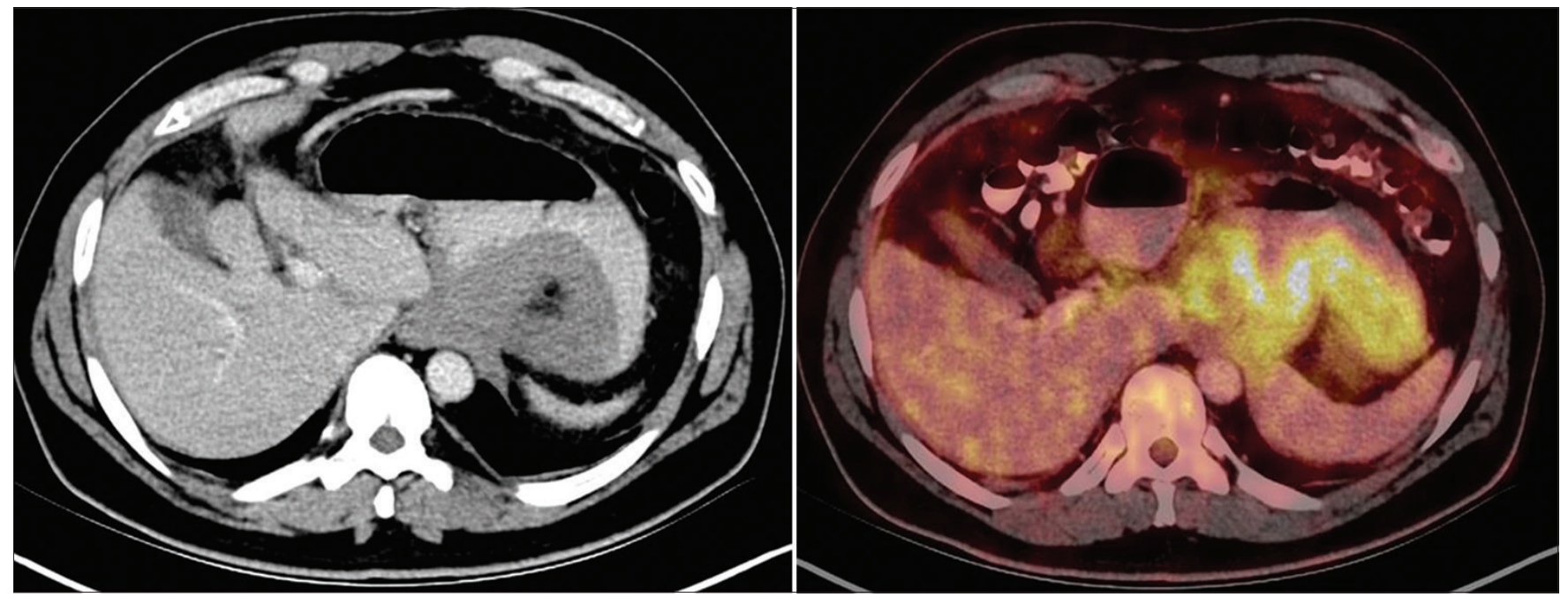

Figure 1: Axial diagnostic computed tomography images show circumferential mass like thickening in the region of gastric fundus. 18-F Fluorodeoxyglucose positron emission tomography-computed tomography shows a metabolically active stomach lesion 

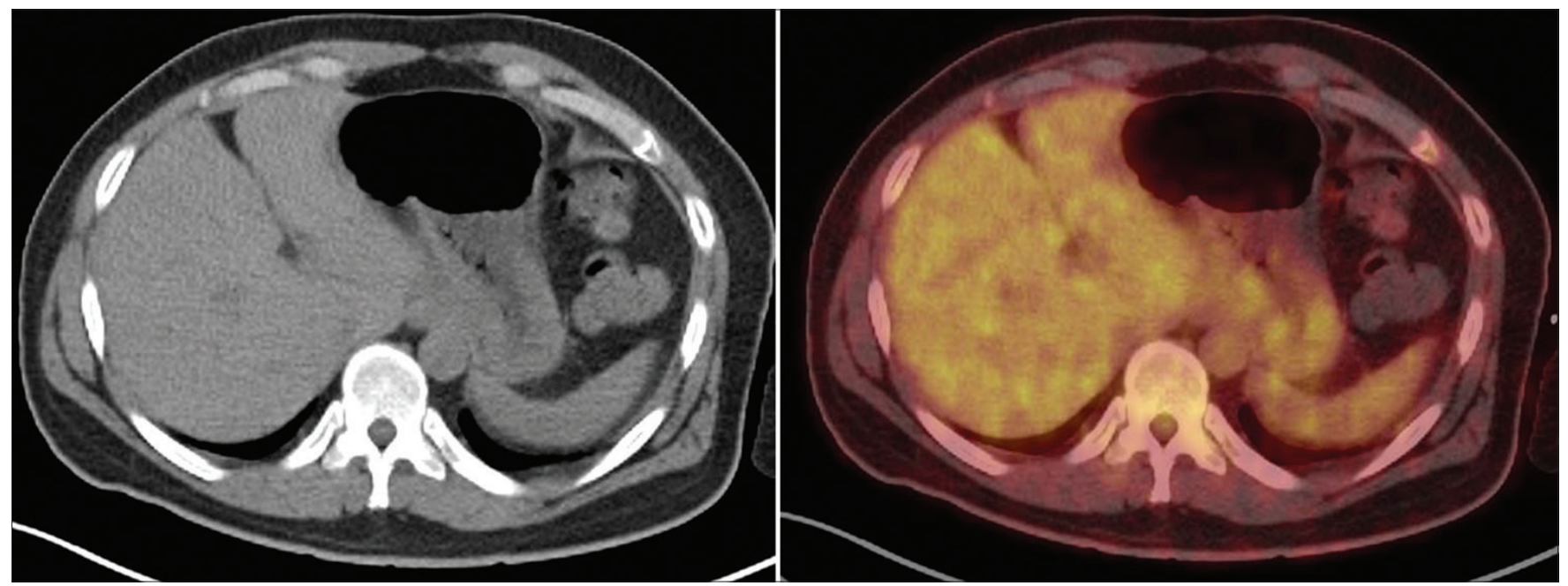

Figure 2: Axial diagnostic computed tomography images show residual mild wall thickening involving fundus and proximal body along lesser and greater curvature of the stomach (maximum thickness $1.4 \mathrm{~cm}$, SUV max 3.3) with heterogeneous tracer uptake

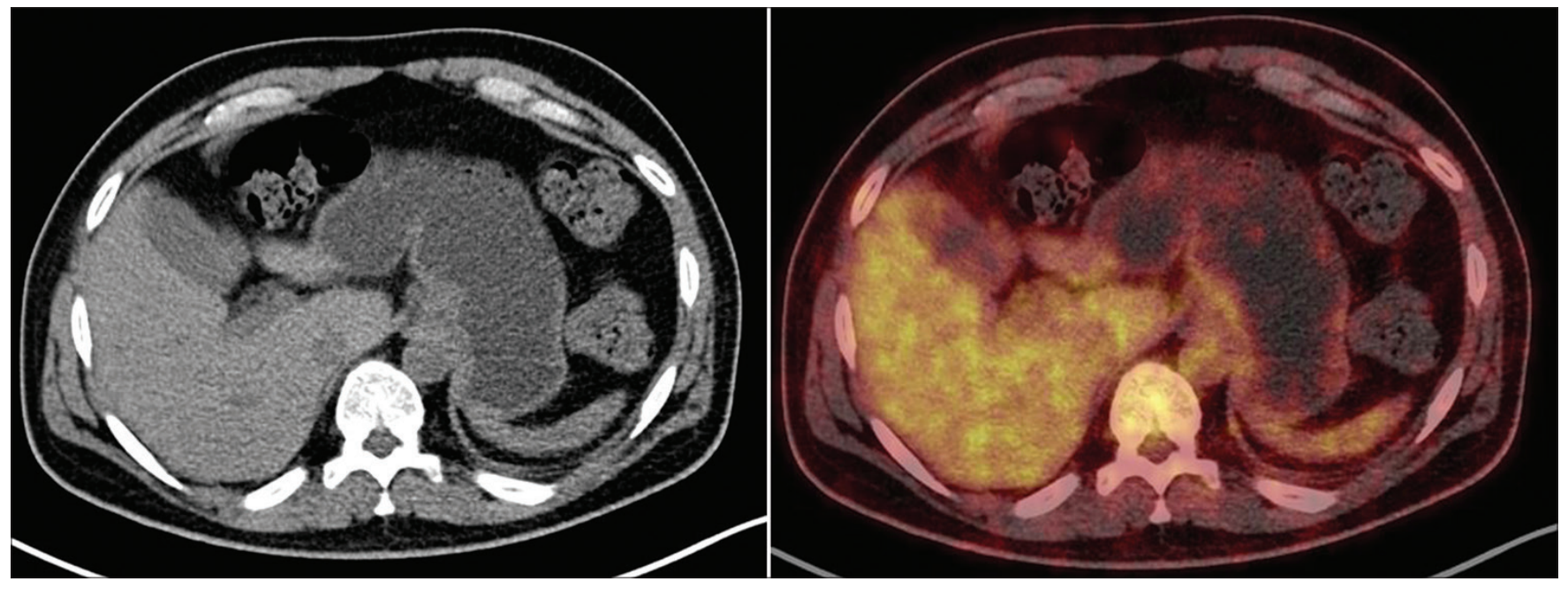

Figure 3: Axial Diagnostic computed tomography images shows ill-defined wall thickening involving fundus and proximal body along lesser and greater curvature of the stomach (maximum thickness $0.8 \mathrm{~cm}$, SUV max 2.3) with heterogeneous tracer uptake

After that, he is on regular follow-up and doing well with no active clinical complaints.

\section{DISCUSSION}

Isolated MS is extremely rare neoplasm consisting of immature myeloid cells occurring at an extramedullary site that most frequently corresponds to the bone, skin, or lymph node although any part of the body may be affected. Histologically, the morphologic subclassification proposed in the third edition of the 2001 World Health Organization classification showed no practical relevance in two recently published studies. ${ }^{[3,4]}$ In contrast, such studies, the results of which have been incorporated in the current fourth edition of the World Health Organization classification, demonstrated that the immunophenotype is of paramount importance for the lineage definition and differential diagnosis.

The Prevalence of Myeloid sarcoma was reported in the range of $2.5-8 \%$ in an autopsy series. ${ }^{[5]}$ Another literature has reported that isolated MS without any blood or BM involvement at the time of diagnosis is a rare disease with an incidence of $2 / 1,000,000$ in adults. ${ }^{[6]}$

The involvement of the stomach is very rare, and to the best of our knowledge, the multimodality imaging features combined with extensive mutational analysis and IHC of isolated MS of the stomach, with follow-up PET-CT imaging has not been reported till date.

Only four cases of isolated MS in the stomach have been reported in literature so far, and no one has provided 
the follow-up in on the grounds of clinical imaging or histopathology. This is also the first case to be reported to have an isolated MS of the stomach with a follow-up BM biopsy revealing a pure red cell aplasia.

Our patient had a large circumferential growth in the fundus of the stomach, which on endoscopy revealed an overlying smooth mucosa suggestive of a submucosal or extrinsic lesion. The imaging and endoscopic information relayed a differential diagnosis of lymphoma, gastrointestinal stromal tumor (GIST), or a rare inflammatory myofibroblastic tumor. ${ }^{[7,8]}$ There was no regional or distant lymphadenopathy on FDG PET-CT investigation. The gastric inflammatory myofibroblastic tumor shows an assortment of features, usually aggressive such as ulceration, adjacent wall infiltration, and extraluminal extension, which were not seen in this case. ${ }^{[9]}$ Gastric GIST, though not very uncommon in this location, is a mesenchymal tumor usually occurring in adolescents and portrays as a submucosal mass with normal overlying mucosa. With GIST of this size and extent, the tumor tends to outgrow the blood supply and shows central necrosis, cavitation, cyst formation, and eventually hemorrhage..$^{[8]}$

Our patient presented with dysphagia as the only symptom and laboratory parameters done did not contribute much in pointing toward a hematolymphoid origin. Such cases pose an invariable diagnostic and therapeutic challenge due to the poor prognostic factor attached to the aggressive behavior of such neoplasm. It must be stressed that IHC came to the rescue and pinpointed the diagnosis of MS, thus enabling the patient to reap the survival benefits.

With the exception of anti-CD43 and anti-lysozyme, more specific markers for myeloid diseases, such as CD33, MPO, CD34, and CD117, are necessary for establishing a correct diagnosis. ${ }^{[10]}$ From a pathologist's perspective, important differential diagnoses include non-Hodgkin lymphoma of the lymphoblastic type, Burkitt's lymphoma, large cell lymphoma, and small round-cell tumors. ${ }^{[1]}$

The median survival for MS patients without AML has been reported to be 36 months while for those progressing toward AML, it is 6-14 months. ${ }^{[12]}$ Our patient has been doing well for the last 4 months postallogenic stem cell transplantation.

A prompt diagnosis and intervention at an early stage will enable the patient to have increased disease-free survival, contemplating the notorious prognosis of this entity.

\section{Declaration of patient consent}

The authors certify that they have obtained all appropriate patient consent forms. In the form the patient(s) has/have given his/her/their consent for his/her/their images and other clinical information to be reported in the journal. The patients understand that their names and initials will not be published and due efforts will be made to conceal their identity, but anonymity cannot be guaranteed.

\section{Financial support and sponsorship}

Nil.

\section{Conflicts of interest}

There are no conflicts of interest.

\section{REFERENCES}

1. Roth MJ, Medeiros LJ, Elenitoba-Johnson K, Kuchnio M, Jaffe ES, Stetler-Stevenson M, et al. Extramedullary myeloid cell tumors. An immunohistochemical study of 29 cases using routinely fixed and processed paraffin-embedded tissue sections. Arch Pathol Lab Med 1995;119:790-8.

2. Vardiman JW, Thiele J, Arber DA, Brunning RD, Borowitz MJ, Porwit A, et al. The 2008 revision of the world health organization (WHO) classification of myeloid neoplasms and acute leukemia: Rationale and important changes. Blood 2009;114:937-51.

3. Pileri SA, Ascani S, Cox MC, Campidelli C, Bacci F, Piccioli M, et al. Myeloid sarcoma: Clinico-pathologic, phenotypic and cytogenetic analysis of 92 adult patients. Leukemia 2007;21:340-50.

4. Falini B, Lenze D, Hasserjian R, Coupland S, Jaehne D, Soupir C, et al. Cytoplasmic mutated nucleophosmin (NPM) defines the molecular status of a significant fraction of myeloid sarcomas. Leukemia 2007;21:1566-70.

5. Meis JM, Butler JJ, Osborne BM, Manning JT. Granulocytic sarcoma in nonleukemic patients. Cancer 1986;58:2697-709.

6. Yilmaz AF, Saydam G, Sahin F, Baran Y. Granulocytic sarcoma: A systematic review. Am J Blood Res 2013;3:265-70.

7. Patnana M, Sevrukov AB, Elsayes KM, Viswanathan C, Lubner M, Menias CO, et al. Inflammatory pseudotumor: The great mimicker. AJR Am J Roentgenol 2012;198:W217-27.

8. Levy AD, Remotti HE, Thompson WM, Sobin LH, Miettinen M. Gastrointestinal stromal tumors: Radiologic features with pathologic correlation. Radiographics 2003;23:283-304, 456.

9. Kim SJ, Kim WS, Cheon JE, Shin SM, Youn BJ, Kim IO, et al. Inflammatory myofibroblastic tumors of the abdomen as mimickers of malignancy: Imaging features in nine children. AJR Am J Roentgenol 2009;193:1419-24.

10. Menasce LP, Banerjee SS, Beckett E, Harris M. Extra-medullary myeloid tumour (granulocytic sarcoma) is often misdiagnosed: A study of 26 cases. Histopathology 1999;34:391-8.

11. Audouin J, Comperat E, Le Tourneau A, Camilleri-Broët S, Adida C, Molina T, et al. Myeloid sarcoma: Clinical and morphologic criteria useful for diagnosis. Int J Surg Pathol 2003;11:271-82.

12. Yamauchi K, Yasuda M. Comparison in treatments of nonleukemic granulocytic sarcoma: Report of two cases and a review of 72 cases in the literature. Cancer 2002;94:1739-46. 